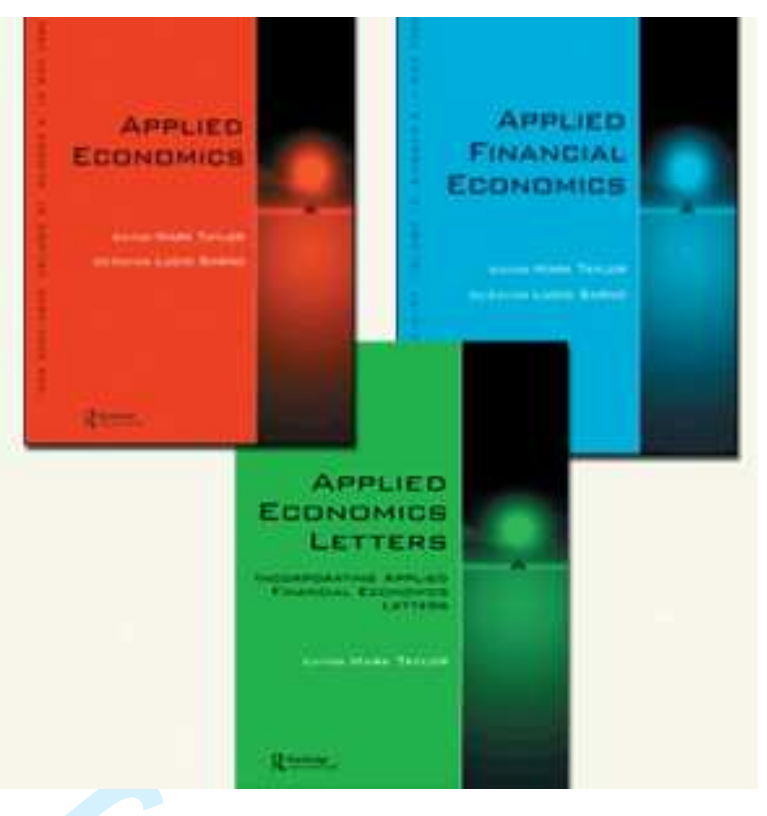

\title{
Do product innovation and news about the R\&D process produce large price changes and overreaction? The case of pharmaceutical stock prices
}

\begin{tabular}{|c|c|}
\hline Journal: & Applied Economics \\
\hline Manuscript ID: & APE-2010-0239.R1 \\
\hline Journal Selection: & Applied Economics \\
\hline $\begin{array}{r}\text { Date Submitted by the } \\
\text { Author: }\end{array}$ & 24-Sep-2010 \\
\hline Complete List of Authors: & $\begin{array}{l}\text { Pérez-Rodríguez, Jorge; Universidad de Las Palmas de Gran } \\
\text { Canaria, Metodos Cuantitativos } \\
\text { Valcarcel, Beatriz; Universidad de Las Palmas de Gran Canaria, } \\
\text { Quantitative Methods for Economics and Management }\end{array}$ \\
\hline JEL Code: & $\begin{array}{l}\text { C22 - Time-Series Models < C2 - Econometric Methods: Single } \\
\text { Equation Models < C - Mathematical and Quantitative Methods, G14 } \\
\text { - Information and Market Efficiency|Event Studies < G1 - General } \\
\text { Financial Markets < G - Financial Economics, I11 - Analysis of } \\
\text { Health Care Markets < I1 - Health < I - Health, Education, and } \\
\text { Welfare }\end{array}$ \\
\hline Keywords: & $\begin{array}{l}\text { Abnormal daily returns, Stock prices and GARCH, GARCH, } \\
\text { pharmaceutical, biotechnology, clinical trials, FDA approvals, FDA } \\
\text { approvals }\end{array}$ \\
\hline
\end{tabular}




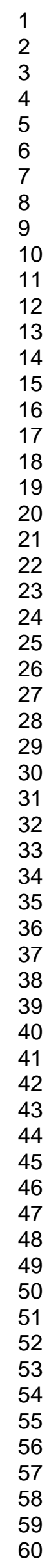

SCHOLARONE ${ }^{m}$
Manuscripts

25

26

27
28

29

30

32

33

34

35

36

37

38

40

41

42

44

45

46

47

48

49

51

52

54

55

57

58

59

60 


\begin{abstract}
:
Do extreme price changes of pharmaceutical stocks reflect unexpected scientific information produced during the drug R\&D process, especially the approval of new drugs, but also pre- and clinical trial results, recalls and withdrawals? Do stock prices initially overreact to such information? We modelled market-adjusted daily changes in stock prices of the seventeen biggest pharmaceutical firms worldwide from 1989 to 2008 to detect large price changes (outliers), using an ARMA-GARCH dynamic econometric model. Then, we matched those outliers with news produced during the drug R\&D process, and tested the hypothesis of no overreaction by examining cumulative abnormal returns. Our results show that there were 261 abnormal market adjusted daily returns. In $60 \%$ of the cases, we were able to assign a plausible cause; i.e., FDA approvals in $6 \%$ of these cases, news of a scientific nature in another $25 \%$. Only 10 of 1721 FDA approvals of new drugs during the study period were related to abnormally large returns. The impact of negative news items on stock prices is larger than of positive news items. The overreaction hypothesis is rejected; there is no price backlash, therefore the efficient market hypothesis is not violated.
\end{abstract}

Keywords: Abnormal daily returns, stock prices, GARCH, pharmaceutical, biotechnology, clinical trials, FDA approvals JEL codes: C22, G14, I11

* Corresponding author. E- mail: jvperez@dmc.ulpgc.es

\footnotetext{
* The authors thank Salvador Torra (University of Barcelona) for kindly providing data, and Pedro Cervera, Ricard Meneu, Vicente Ortún and Jaume Puig for their comments and suggestions. We gratefully acknowledge Bill Christian for his help with the English text. We also gratefully acknowledge financial support from the Spanish Ministry of Science and Technology (SEJ2006-07701/ECON) and from the unconditional grant of the Merck Foundation to the CRES, University Pompeu Fabra, Spain. The views expressed here are those of the authors and not necessarily those of the institution with which they are affiliated.
} 


\section{Do product innovation and news about the $R \& D$ process produce large price changes and overreaction? The case of pharmaceutical stock prices}

\section{Introduction}

The economic literature has profusely documented the positive correlation between innovation and company profitability (Geroski et al. 1993; Roberts, 1999; Grabowski et al., 2002, among others). However, empirical evidence linking individual new products and company performance is not so generally available. Recent studies empirically examined the effects of new product development outcomes (approval or rejection of new drugs, or the expression of serious concerns about their application) on the overall commercial performance of pharmaceutical companies (Sharma and Lacey, 2004). Others have highlighted the financial impact of new product presentations and the supporting role of company resources and organizational structure, by analyzing business sectors such as agriculture, food manufacturing or pharmaceutics (Lee and Chen, 2009). However, these studies have only analyzed the impact of product approval on stock prices on or around the announcement or commercialization date. Our aim is to generalize them to the whole R\&D process.

The pharmaceutical industry is a good setting for that research; managers and investors in pharmaceutical and biotech firms might be expected to be particularly sensitive to the R\&D process. In all R\&D processes there are two particularly significant moments, those of discovery and innovation. In the case of the pharmaceutical industry these tend to be considerably separated in time, because the R\&D of new drugs is a very lengthy (and costly) process. Unlike product developments in most other industries, the $\mathrm{R} \& \mathrm{D}$ process in the pharmaceutical industry contains clearly separated but highly correlated sequential phases. $R \& D$ in the pharmaceutical industry is riskier than in many other hightech industries, the process is lengthy, expensive and very uncertain in terms of human physiological 
responses to drugs (Trusheim et al., 2007). Moreover, there is intense global competition, and strict government regulations are applied (Xu, 2006).

This paper contributes to the literature on product innovation by empirically analyzing the relationships between large stock price changes and news produced during the drug R\&D process. We study, on the one hand, whether drug innovation (the approval of a new drug) and other news items produced during the drug $R \& D$ process (i.e., other scientific news such as pre- and partial clinical trial results, recalls and withdrawals of new products) are related to extreme stock price changes, and on the other, whether there are short-term price movements in the opposite direction following an extreme one-day price movement (the overreaction and backlash hypothesis), that is, whether there exist systematic, and therefore predictable, patterns before and after such events.

Knowledge of these extreme prices could be important to pharmaceutical managers responsible for new products, who need to create realistic expectations about new products (Sharma and Lacey, 2004) and so could be interested to know whether large price fluctuations accurately reflect new and unexpected scientific information or whether stock prices overreact to such information. Managers of multinational pharmaceutical companies, which generally have high liquidity and a diversified drug portfolio, could also be interested in knowing whether other news during the drug R\&D process could affect their stock prices. A better understanding of the market overreaction effect has important implications and could be useful not only for managers, scholars and professionals, but also for the investors who wish to design investment strategies.

Our paper also contributes to the literature on large price changes by introducing a new method based on dynamic trigger values aimed at detecting abnormally large returns. In contrast to the approach taken by Wong (1997), our method allows us to consider the conditional risk associated with stock prices. The model used in this study is an ARMA-GARCH type dynamic econometric model for the daily market-adjusted percentage change in stock price, aimed at identifying abnormal spikes and drops. 
In Section 2 we briefly describe the empirical literature on large price changes and the linear $R \& D$ process in the pharmaceutical industry, and we formulate our hypothesis. In Section 3 we describe data and methods we used to identify abnormal daily returns, and then test the overreaction hypothesis. In Section 4 we provide the empirical results obtained, and these are discussed in Section 5.

\section{Extreme price changes and the drug $R \& D$ process}

\subsection{Large price changes in the economic and financial literature}

In general, large one-day price changes are caused by unexpected firm-specific or market information, for example, operating results or unanticipated governmental decisions (Atkins and Dyl, 1990; Bremer et al., 1997, among others). In addition, unanticipated changes in the regulation of a business sector may cause a concurrent and abnormal change in stock prices, positive or negative (Dowdell et al., 1992). Empirical financial literature has analyzed these events in two ways: on the one hand, event study methodologies assess the share price impact of firm-specific events, thus allowing the researcher to measure the effects of a given economic event on the company's value. The usefulness of such a study comes from the fact that, given rationality in the marketplace, the effects of an event will be reflected immediately in stock prices (MacKinlay, 1997). Studies have been devoted to investigating abnormal returns following large price changes, and some studies have examined whether short-term price movements in the opposite direction or price reversals occur following a one-day extreme price movement (i.e., the overreaction hypothesis). The issue of stock market overreaction is not a new one (Beaver and Landsman, 1981; DeBondt and Thaler, 1985), and two measures for large price changes have been established: firstly, daily rates of returns are greater/less than or equal to predetermined trigger values (for example, $\pm 10 \%$ ). Using this methodology, authors such as Atkins and Dyl (1990), Bremer and Sweeny (1991), Cox and Peterson (1994), Bremer et al. (1997), Challet and Stinchcombe (2003), Farmer et al. (2004), Weber and Rosenow (2006) and Zawadowski et al. (2006), 
have reported significant price reversals during the first three post-event days on all stock markets investigated, including NYSE, AMEX, NASDAQ and TSE. Secondly, other studies have used dynamic trigger values based on a company's expected returns and volatility; for example, Wong (1997) defined all daily rates of return that were significantly greater/less than their sample mean returns of about $2.5 \%$ as large price increases/decreases over the period.

\subsection{The drug $R \& D$ process and abnormal returns in the pharmaceutical industry}

The formal R\&D process of a drug is its movement through the pipeline towards final approval. The process, which is strictly regulated at every stage by the corresponding governmental authority, can thus be viewed as a linear model (Hara, 2003) (Figure 1).

From the discovery of a new drug (patent) to the innovation (approval) time, some 12-15 years may pass. After product approval by governmental authorities, commercialization may then begin. Clinical trials will continue to be performed, and the drug may be found to have serious side effects, forcing the authorities to have it withdrawn from the market. Each stage/phase takes an average of 2-3 years, and exhibits a differential success rate (DiMasi, 1995).

Figure 1. Formal drug R\&D process.

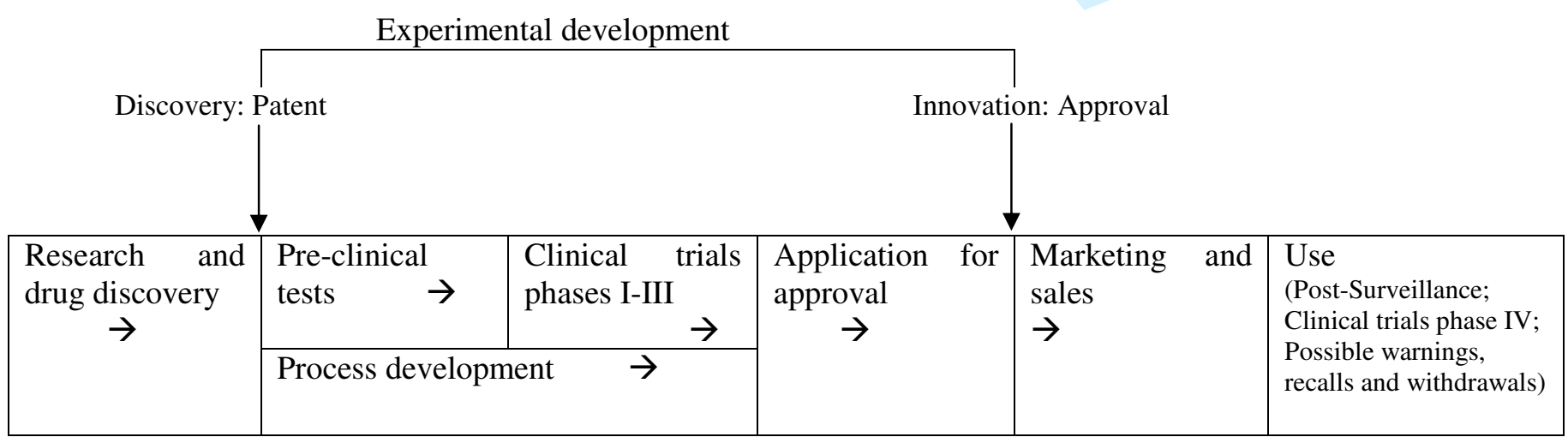

Source: Adapted from Hara (2003). 
With respect to product innovation, a small number of studies have used event studies to examine the impact of new products on company value. The results obtained have been mixed. For example, Eddy and Saunders (1980) found no evidence that announcements of new products changed monthly stock returns. Woolridge and Snow (1990) found that the stock market reacted positively to the news of product and/or market diversification, while Chaney et al. (1991) found new product announcements were expected to generate positive abnormal stock returns. All three studies focused on positive announcements, but ignored the consequences of negative ones related to the non-delivery of a new product that had been anticipated. In this sense, Sharma and Lacey (2004) highlighted the importance of the effects of new product development successes and failures on overall pharmaceutical company performance.

Other studies analyzed overall R\&D progress: Chan et al. (2001); Shi (2003). Xu (2006) studied the effects of $R \& D$ progress on the dynamics of stock price volatility of biotech companies and the post announcement drift. And on the other hand, by analyzing just certain aspects within the R\&D process. For example, some studies have focused on the effects of regulatory decisions on stock prices (fundamentally, by the Food and Drug Administration, FDA) such as drug approvals (Sharma and Lacey, 2004; Ahmed, 2007) or drug recalls and withdrawals (Jarrell and Peltzman, 1985; Marcus et al., 1987; Dowdell et al., 1992; Dranove and Olsen, 1994; or Ahmed et al., 2002; among others). ${ }^{1}$

According to the efficient market hypothesis $(\mathrm{EMH})$, stock prices reflect the correct valuation of a company and its future cash flows, in view of currently available public information. Large, abrupt changes in prices are the market reaction to unanticipated news that surprises the market. Are unexpected $R \& D$ news related to large price changes, and there exist short-term price movements in the opposite direction following an abrupt, extreme price movement? Our paper explores these questions.

\footnotetext{
${ }^{1}$ Some studies have analyzed the effects of strategic alliances between pharmaceutical and biotech companies (Nicholson et al., 2005) or company strategies (Oberholzer and Inamdar, 2004; Efremidze, 2007). 


\subsection{Hypotheses of our study}

H1: Some extreme price movements reflect unexpected scientific new information produced during the drug $R \& D$ process, and affect the daily close-to-close stock prices of pharmaceutical firms. $^{2}$

H2: There is a short-term backlash market reaction following extreme price variations of pharmaceutical stock prices related to drug innovation and other scientific news produced during the $R \& D$ process. Long-term traders profit from the predictable patterns identifiable in stock returns in such events.

These two hypotheses are set against the null hypotheses that the market in pharmaceutical stocks does not respond abnormally to drug innovation news, and that the stock market does not feature an overreaction/backlash pattern with respect to drug innovation news (i.e., price reversal in the market does not take place).

\section{Material and methods}

\subsection{Data}

In our study we matched two databases, the first containing stock prices and stock market indexes, and the second, the launching of new products and news about scientific fundamentals in the pharmaceutical sector.

\subsubsection{Stock prices and indexes}

Our primary data set consisted of the daily closing prices adjusted for dividends and splits of various stock indexes and stock prices (Table 1). The specific firms we modelled were the largest ones

\footnotetext{
${ }^{2}$ For example, announcements or news about clinical or scientific developments; new knowledge about drug efficacy and adverse effects; and FDA or European Medicines Agency (EMEA) decisions and regulations on the commercialization of a new medicine, among others) 
in the US market according to the Forbes ranking of 2005 (www.forbes.com/lists). The data were obtained from Reuters (American composite indexes) and Bloomberg (US and European stock prices and European composite indexes). The time period covers 18 years in which there were important discoveries and advances in therapy, as well as withdrawals of drugs from the market and serious warnings of adverse effects. All data are collected to March 25, 2008.

Table 1. Indexes and top pharmaceutical companies included in this study.

\begin{tabular}{|c|c|c|}
\hline Name & Market & Since \\
\hline NYSE COMPOSITE & NYSE & January 3, 1966 \\
\hline NASDAQ Global Select Market & NASDAQ GS & February 4, 1985 \\
\hline SMI & VIRT-X & July 1,1988 \\
\hline FTSE & LSE & January 3, 1984 \\
\hline $\mathrm{CAC}$ & Euronext Paris & July 9, 1987 \\
\hline NIKKEI & TSE & January 1,1980 \\
\hline ABBOTT LABORATORIES & NYSE & July 28,1980 \\
\hline AMGEN INC & NASDAQ GS & January 3, 1984 \\
\hline ASTRAZENECA PLC & LSE & May 12,1993 \\
\hline BAYER AG-SPONSORED ADR & NYSE & May 9, 1995 \\
\hline BRISTOL-MYERS SQUIBB CO & NYSE & July 28,1980 \\
\hline GENENTECH INC & NYSE & July 19, 1999 \\
\hline GLAXOSMITHKLINEPLC & LSE & October 28, 1991 \\
\hline JOHNSON \& JOHNSON & NYSE & March 3, 1977 \\
\hline ELI LILLY \& CO & NYSE & July 28,1980 \\
\hline MERCK \& CO. INC. & NYSE & July 28,1980 \\
\hline NOVARTIS AG-REG & VIRT-X & October 23,1989 \\
\hline PFIZER INC & NYSE & July 28,1980 \\
\hline ROCHE HOLDING AG-GENUSSCHEIN & VIRT-X & October 23,1989 \\
\hline SANOFI-AVENTIS & Euronext Paris & October 2, 1989 \\
\hline SCHERING-PLOUGH CORP & NYSE & July 28,1980 \\
\hline TAKEDA PHARMACEUTICAL CO LTD & TSE & January 31,1984 \\
\hline WYETH & NYSE & July 28,1980 \\
\hline
\end{tabular}

\subsubsection{Approval of new drugs and scientific news}

We created a database with information on all FDA-approved new drugs from 1989 to 2008. We also created a database with news related to the efficacy and therapeutic value of drugs, including items reported by the press and information released by the companies. Our sources were the FDA, the EMEA, The New York Times, The Financial Times, The Wall Street Journal, and the web pages and 
press releases of the 17 companies under consideration. ${ }^{3}$

\section{1) Approval of new drugs}

Class 1 (or priority) "good news": approval of any new drug classified by the FDA as a "priority review drug", that is, any "drug that appears to represent an advance over available therapy," an innovation that promises to be disruptive. The FDA terms as priority review drugs those that fill an unmet need or that work better than competing drugs on the market. Priority review takes an average of six months, compared with the twelve-month standard review. In the database, the approval date was registered as the date of the event. We also included as class 1 "good news" the approval of biologics.

The approval of any other new drug (standard review) was considered class 2 "good news" and included in our database. Between 1989 and 2007, a total of 1721 new drugs were approved, of which 67 were biologic and 1654 chemical. Of the latter, 1297 (78.4\%) were classified as standard and 357 (21.6\%) as priority. The 17 companies in our study developed 620 new drugs, including 104 priority drugs that we consider class 1 "good news".

For a comparison based on the market rather than on medical innovation, we created an additional list of the approval dates of the top 200 drugs by sales in 2007 in the US market (Source: IMS Health Inc.). The top ten by sales are listed in Table 2.

\footnotetext{
${ }^{3}$ Our interest is in relating medical innovation to short term changes in stock prices. What scientific drug results surprise or frighten the market? To find out, we compared changes in the stock prices of pharmaceutical companies with the composite index for each stock market, taking into account that good news for one company can be bad news for others.
} 
Table 2. Top ten 2007 drugs, ranked by sales in the US market.

\begin{tabular}{cllccl}
\hline \hline Number Brand name & Approval date & $\begin{array}{l}\text { Chemical } \\
\text { type }\end{array}$ & $\begin{array}{l}\text { Review } \\
\text { classification }\end{array}$ & Company \\
\hline 1 & Lipitor & December 17, 1996 & 1 & $\mathrm{P}$ & PFIZER \\
2 & Nexium & February 20, 2001 & 2 & $\mathrm{P}$ & ASTRAZENECA \\
3 & Advair Diskus & August 24, 2000 & 4 & $\mathrm{~S}$ & GLAXOSMITHKLINE \\
4 & Plavix & November 17, 1997 & 1 & $\mathrm{P}$ & SANOFI AVENTIS \\
5 & Seroquel & September 26, 1997 & 1 & $\mathrm{~S}$ & ASTRAZENECA \\
6 & Singulair & February 20, 1998 & 1 & $\mathrm{~S}$ & MERCK \\
7 & Enbrel & November 2, 1998 & $\mathrm{B}$ & & INMUNEX \\
8 & Prevacid & May 10, 1995 & 1 & $\mathrm{~S}$ & TAP PHARM \\
9 & Aranesp & September 17, 2001 & $\mathrm{B}$ & & AMGEN \\
10 & Epogen & June 1, 1989 & $\mathrm{B}$ & & AMGEN \\
\hline \hline
\end{tabular}

Note: The data sources are IMS Health Inc and FDA. Chemical types are $1=$ new molecular entity, $2=$ new ester, new salt, or other noncovalent derivative, $4=$ new combination; and $B=$ biologic; and the review classifications are $\mathrm{P}=$ priority review drug ("A drug that appears to represent an advance over available therapy"), and $S=$ standard review drug ("A drug that appears to have therapeutic qualities similar to those of an already marketed drug").

\section{2) Other "good news" on advances in medical knowledge}

Another kind of good news related to medical innovation is the publication of promising partial results of clinical trials. We searched the clinical trial database (http://clinicaltrials.gov/) and major medical journals (through Medline) for scientific news related to experimental drugs that were published on or around the day of an extreme abnormal return.

\section{3) “Bad news"}

Bad news includes unexpected bad results of clinical trials, and alerts, warnings and withdrawal decisions taken by regulatory agencies. Bad news about a specific drug typically begins with a negative result -adverse effect- in a medical journal, followed by one or more warnings from the FDA or other regulatory agency. During the period under study, several severe, well-publicized safety issues alarmed consumers.

Some warnings are specific to a particular company (as with Bayer's Baycol), and others are more general. Examples of the latter were the warning about the risk of child and adolescent suicide due to antidepressants (Summer, 2006), evidence of serious adverse effects of hormone substitution therapy, 
and the FDA public health advisory notice to limit the use of Cox-2 inhibitors, issued in December 2004, due to the risk of cardiovascular events.

We used three sources of data for bad news:

1. FDA Recalls, Market Withdrawals and Safety Alerts information

(http://www.fda.gov/medwatch/safety.htm), including the Adverse Event Reporting System Quarterly

Data Files (http://www.fda.gov/cder/aers/extract.htm). The FDA usually publishes one or more new items every week, and almost every working day there is an entry in the database. We restricted our search to Class I recalls. ${ }^{4}$

2. The European Medicines Agency database of withdrawals from July 7, 2000 to January 31, 2008 (http://www.emea.europa.eu/htms/human/withdraw/withdraw.htm). During this period the EMEA withdrew 41 drugs, 18 of them sponsored by firms in our study. We checked for any match between the withdrawal dates and the dates of abnormal price falls.

3. Other sources: The National Library of Medicine database clinical alerts on drugs, media sources (Archives of The New York Times, The Financial Times and The Wall Street Journal), and the relevant company websites.

\subsection{Methods}

\subsubsection{Detecting extreme returns with dynamic trigger values based on standardized abnormal returns}

In this paper, we identify extreme abnormal daily returns by using dynamic trigger values determined by analysis of each company's standardized market-adjusted returns. For this purpose, a dynamic econometric model for market-adjusted changes in daily stock prices was constructed, in order to detect extreme observations (outliers). A simple algorithm based on standardized abnormal returns

\footnotetext{
${ }^{4}$ Recalls are "actions taken by a firm to remove a product from the market. Recalls may be conducted on a firm's own initiative, by FDA request, or by FDA order under statutory authority". A Class I recall is "a situation in which there is a reasonable probability that the use of or exposure to a violative product will cause serious adverse health consequences or death"). http://www.fda.gov/oc/po/firmrecalls/recall_defin.html
} 
was then used to determine whether or not each of these trading days was an outlier. ${ }^{5}$ When extreme observations were detected, they were matched with the news databases.

Let $R_{m t}$ and $R_{i t}$ be the market index return and the stock return, respectively, for security $\mathrm{i}$ ( $i=1,2, . ., N$, where $N$ is the number of shares) for day $\mathrm{t}(t=1,2, . ., T$, where $T$ is the sample size or the number of daily observations in the estimation period).

Our approach for identifying outliers is based on the following steps:

Step 1. Estimate an $\operatorname{ARMA}(p, q)-\operatorname{GARCH}(1,1)$ model for the market-adjusted returns $\left(A R_{i t}=R_{i t}-R_{m t}\right)$. These models can be written as:

$$
\begin{aligned}
& A R_{i t}=\mu+\phi_{1} A R_{i t-1}+\ldots+\phi_{p} A R_{i t-p}+\varepsilon_{i t}-\theta_{1} \varepsilon_{i t-1}-\ldots-\theta_{q} \varepsilon_{i t-q}, t=1, \ldots, T \\
& \varepsilon_{i t} / \psi_{t-1} \sim N\left(0, \sigma_{i t}^{2}\right) \\
& \sigma_{i t}^{2}=w+\alpha \varepsilon_{i t-1}^{2}+\beta \sigma_{i t-1}^{2}
\end{aligned}
$$

where $\mu$ is a constant term; $\phi_{j}, j=1, \ldots, p ; \theta_{j}, j=1, \ldots, q$ are $\mathrm{AR}$ and MA parameters, respectively; $\psi_{t-1}$ is the information set at $t-1 ; \varepsilon_{i t}=z_{i t} \sigma_{i t}$ is an idiosyncratic error with $z_{i t} \sim N(0,1)$; and $\sigma_{i t}^{2}$ is the conditional variance for the $i$-th stock, where $\omega, \alpha$ and $\beta$ are unknown parameters, and $\alpha+\beta<1$ is the persistence condition. The estimation was made by maximum likelihood (by using the Berndt, Hall, Hall and Hausman algorithm).

Step 2. We calculated the standardized residuals (re-scaled abnormal returns) as $\hat{z}_{i t}=\hat{A}_{i t} / \hat{\sigma}_{i t}$, where $\hat{A}_{i t}=A R_{i t}-A \hat{R}_{i t}$ is the abnormal return $\left(A \hat{R}_{i t}\right.$ is the market-adjusted return), and $\hat{\sigma}_{i t}$ is the conditional standard deviation. ${ }^{6}$

\footnotetext{
${ }^{5}$ There are other methods to detect abnormal price fluctuations, such as event studies, which we have also used, as a complementary method.

${ }^{6}$ If the model is correctly specified, the standardized residuals should be independent, and have identically distributed random variables with mean zero and variance one. If the standardized residuals are also normally distributed, then the estimates are maximum likelihood estimates that are asymptotically efficient. However, even if the distribution of the residuals is not normal, the estimates will still be consistent under quasi-maximum likelihood assumptions.
} 
Step 3. Taking into account the empirical distribution of $\hat{z}_{i t}=\hat{A}_{i t} / \hat{\sigma}_{i t}$, we examined the extreme observations. More specifically, we considered as outliers for the i-th company those which exceeded \pm 4 standard deviations from the mean of $\hat{z}_{i t}=\hat{A}_{i t} / \hat{\sigma}_{i t} \cdot{ }^{7}$

\subsubsection{Cumulative abnormal returns (CAR) following large price changes}

In order to investigate whether abnormal returns are present, the returns on days following a large price change were compared with the expected return, estimated using the market model. We used the Filson (2004)'s event study methodology to calculate the cumulative abnormal return around the large abnormal return detected, and to test the overreaction hypothesis. The regression equation is written for the $\mathrm{i}$-th stock as $R_{i t}=\alpha_{i}+\beta R_{m t}+\sum_{j=1}^{J} \gamma_{i j} D_{i, j t}+u_{i t}$, where $\mathrm{J}$ is the number of events for company $\mathrm{i}, D_{i, j t}$ is a dummy variable which takes the value of one during the event window $\mathrm{j}$ (which includes $\tau_{1}$ days before the event and $\tau_{2}$ days after it), $\alpha_{i}, \beta_{i}$ and $\gamma_{i j}$ are estimated coefficients, and $u_{i t}$ is the error term on date t. $C A R_{i j}\left(\tau_{1}, \tau_{2}\right)$ of event $\mathrm{j}$ for the $\mathrm{i}$-th stock is calculated by multiplying $\gamma_{i j}$ by the length of the event window, which is $\tau_{2}-\tau_{1}$ days. Therefore, $C A R_{i j}\left(\tau_{1}, \tau_{2}\right)=\gamma_{i j} \times\left(\tau_{2}-\tau_{1}\right)$. Its variance is equal to $\operatorname{var}\left(C A R_{i j}\left(\tau_{1}, \tau_{2}\right)\right)=\operatorname{var}\left(\gamma_{i j}\right)$ and, therefore, the t-statistic value of event $\mathrm{j}$ is the same as that of $\gamma_{i j}$. Overlapping events are ranked by importance and only the highest ranking event is included. This estimation method eliminates double counting of abnormal returns on overlapping events. The mean cumulative abnormal returns for all companies ( $\overline{C A R}$ or cross-section mean CAR) with respect to the pre and post-event periods $\left(\overline{C A R}\left(-\tau_{1},-1\right)\right.$ and $\overline{C A R}\left(-\tau_{1},+\tau_{1}\right)$, respectively) are calculated. Simple cross-sectional t-statistics are used to test the significance of the mean CAR for different periods. Other

\footnotetext{
${ }^{7}$ Taking directly stock returns (and not standardized abnormal returns), Bremer and Sweeney (1991), Cox and Peterson (1994), Park (1995) and Bremer et al. (1997) consider as triggers values around \pm 10 percent. Wong (1997) uses dynamic trigger values around 2.5 . 
measures obtained are the mean abnormal return at the event time $(\overline{A R}(0) \equiv \overline{C A R}(0,0))$ and after one day $(\overline{A R}(1) \equiv \overline{C A R}(+1,+1))$.

\subsubsection{Matched samples to search for predictable patterns}

We matched the database containing the dates of outliers with the database of news items describe in section 3.1.2. Although there may be some delay in the circulation of news to patients and doctors (Embi et al., 2006), market watchers tend to get information quickly. We therefore assumed that market reactions began on the same day as news disclosures, but we also checked for possible leads and lags of two trading days.

\subsubsection{Overreaction hypothesis}

We analyzed both pre and post-event periods. Pre-event periods are interesting because they may indicate insider's information held by some agents, and post-event periods shed light on matters such as market efficiency. The overreaction hypothesis implies a violation of the Efficient Market Hypothesis $(\mathrm{EMH})$, suggesting that, in some circumstances, future stock prices cannot be predicted from past stock prices. We tested this hypothesis by analyzing whether there are short-term price movements in the opposite direction, i.e. whether price reversals occur, following a one-day extreme price movement. Under the EMH, a large price change should not be a trading signal after which a systematic, and potentially profitable, pattern is present in the data. If there are large stock price increases and $\overline{C A R}\left(+1, \tau_{2}\right)$ (where $\left.\tau_{2}=+1,+2,+5,+10\right)$ are statistically significant and their signs are negative, then there exists price reversal or overreaction. If there is a large fall in the stock value and $\overline{C A R}\left(+1, \tau_{2}\right)$ (where $\tau_{2}=+1,+2,+5,+10$ ) are statistically significant and their signs are positive, then there exists price reversal or overreaction. Otherwise, no overreaction is found. 


\section{Results}

\subsection{Large abnormal returns during the $R \& D$ process}

We identified a total of 261 outliers in the market-adjusted returns of the 17 pharmaceutical companies. $^{8}$ The average number of extreme abnormal returns per company in the period under study was 15.3 (Takeda with 7.3 had the fewest, Roche with 24 , the most). From our documentary sources, a plausible cause was found for $62 \%$ of these outliers. ${ }^{9}$

$51(21 \%)$ of the extreme abnormal returns correspond to causes identified as new scientific information, while $43 \%$ were economic in nature. Of the scientific news items, 20 were good and 31 bad. Most of the abnormal price changes occurred on the same day or the day after the news item, but occasionally the price spike or drop anticipated the news by a day.

\section{Approvals of new drugs}

The approval by the FDA of innovative priority drugs in few cases has a significant impact in the \pm 2 days interval around the approval date, whether on the stock price of the innovative company or on those of its competitors. Innovations and clinical good news appear to be factored into stock prices well in advance of the approval date, so that approval "news" fails to surprise the markets. The same holds for the approval days of the top ten drugs in the US market.

Only 9 approval dates among those for the 620 priority and standard new drugs were associated with positive abnormal spikes in the stock prices of the companies in question (Figure 2). Of these 9 drugs, 4 were biologics, all targeted at cancer, and the others were on the list of the 200 drugs most sold in 2008 .

\footnotetext{
8 As we suspected that the residuals were not conditionally normally distributed, we computed the quasi-maximum likelihood covariance and standard errors by the method in Bollerslev and Wooldridge (1992).

${ }^{9}$ A detailed table with links to online sources is available on request. 
Figure 2. Extreme abnormal returns associated with FDA approvals (Period 1989-2008).

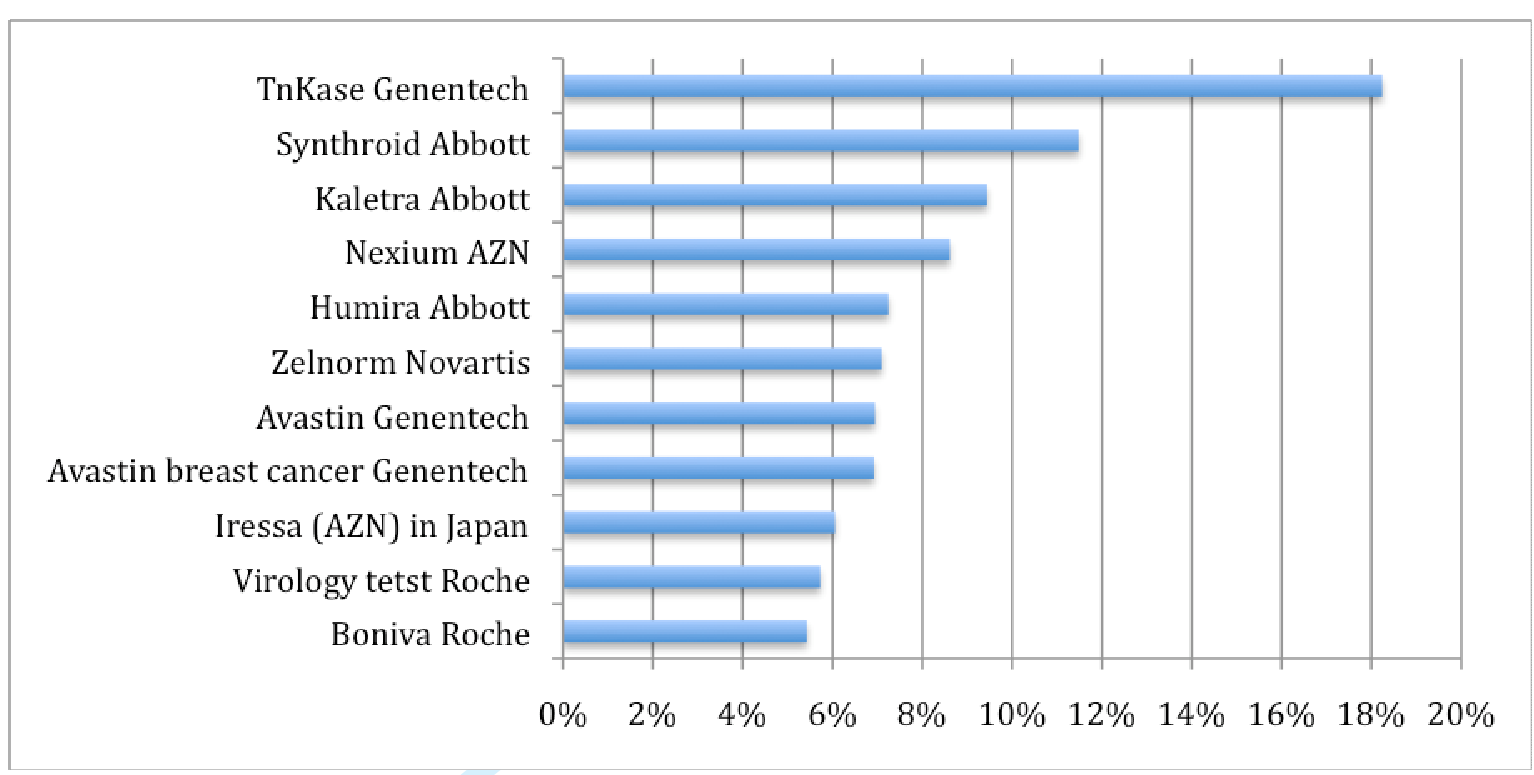

\section{Clinical trials results, recalls and withdrawals}

In some cases, extreme abnormal price spikes prior to the approval of a new medicine corresponded to better than expected results of clinical trials. An example of this is ReoPro (Abciximab), a monoclonal antibody marketed by Eli Lilly and produced by Centocor Inc. It was first approved on May 11, 1997. On that date no outlier was detected, but a year and a half earlier, on October 25, 1995, unexpectedly good results from a clinical trial boosted Eli Lilly and Centocor stocks. Another example is Eli Lilly's Zovant, the tentative name for the first drug against sepsis. It was ultimately approved by the FDA on November 21, 2001 (no abnormal price spike) with the name Xigris. The market had earlier acknowledged the success of clinical trials with abnormal returns on June 29, 2000. New biotech drugs to treat cancer and other conditions did surprise the markets. We identified 10 positive outliers (4 from Genentech) associated with the announcement of clinical trial results for cancer treatments (Figure 3). 
Figure 3. Extreme abnormal returns associated with scientific news (Period 1989-2008).

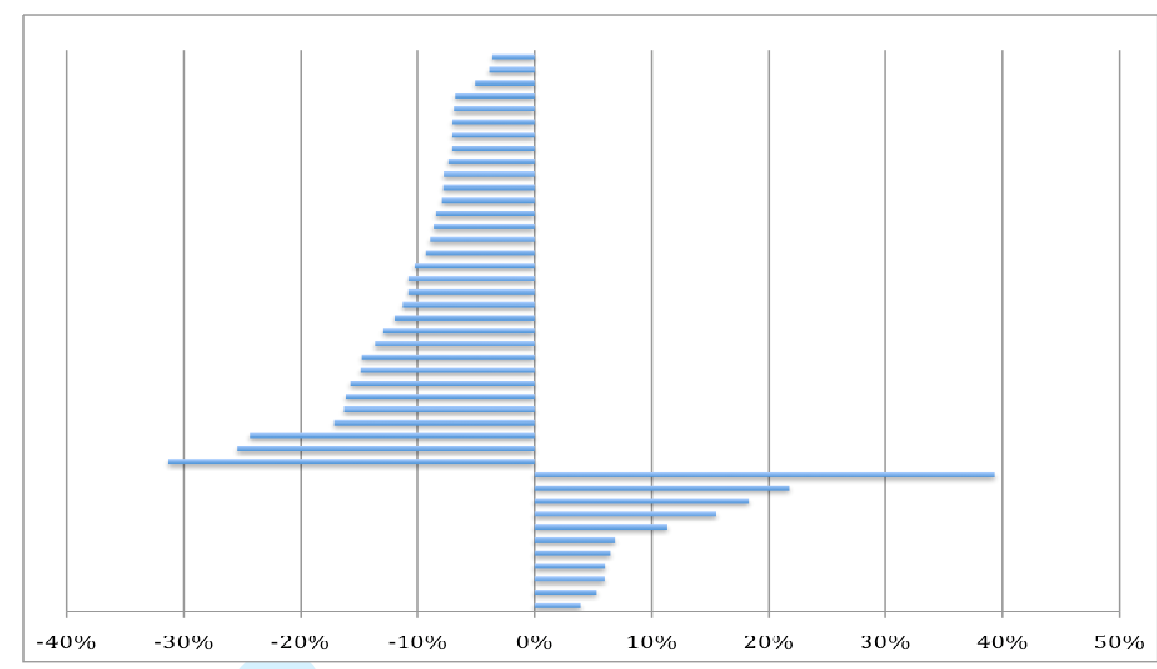

The greatest extreme returns were those of biotech monoclonal antibodies for cancer treatment. Avastin, a treatment for colon and colorectal cancer (May 19, 2003) provided an abnormal spike for Genentech of $+39 \%$; two years later, positive results for a lung cancer medicine (March 14, 2005) led to a $+21.8 \%$ abnormal spike; and a month later, on April 15, the results of the preliminary trial of a treatment for breast cancer gave Genentech another price spike, this time of $18.3 \%$. Because Roche owned a majority of Genentech, Roche's price also soared.

Negative results of clinical trials, the withdrawal of drugs from the market, delays and FDA recalls were responsible for 31 negative outliers, 8 of them with abnormal drops greater than $15 \%$, and 9 others between 10 and $15 \%$. These three types of results affected almost all the companies under study.

Thus, the withdrawals from the market, voluntary or imposed, of Omniflox (Abbott, June 8, 2002), Baycol (Bayer, August 8, 2001), Leukine (Bayer, January 22, 2008), Propulsid (Janssen, a subsidiary of Johnson \& Johnson, announced March 24, 2000), and Vioxx (Merck, September 30, 2004) led to extreme abnormal drops in stock prices. The market tended to fall lower than the expected loss to cash flow, not just because of an expected drop in sales, but also because of the risk of litigation and the loss of goodwill affecting the company as a whole. 
Other outliers associated with company news announcements concerned the failures of clinical trials. This was the case of AstraZeneca's clinical trial NXY-059 (October 26, 2006). The most dramatic stock price fall was Merck's Vioxx (31.3\% drop in a single day), followed by the July 9, 2002 publication of a study of the risk of breast cancer associated with the hormone substitution drug Prempro (Premarin) (a 25.4\% drop for Wyeth); third place corresponded to the April 19, 2000 postponement of the approval process of Vanlev following poor clinical trial results (Bristol fell 24\%); and fourth place to Bayer's withdrawal of Baycol (17\%).

Several other bad news items are related to FDA decisions, for example FDA restrictions on the use of Aranesp in cancer patients (May 10, 2007); the FDA's delay in granting approval of Eli Lilly's Duloxetine (September 3, 2003); the FDA's rejection of the anti-obesity drug Rimonabant (SanofiAventis, June 14, 2007); the FDA's warning about cardiac events caused by Pioglitazone $\mathrm{HCl}$ (marketed as Actos and Actoplus, Takeda, August 14, 2007); and the FDA's rejection of the Wyeth drug Pristiq for treatment of hot flushes and other menopausal symptoms (July 24, 2007).

\subsection{Price reversal: are there predictable patterns? Testing the EMH}

Table 3 has two panels: Panel A shows results based on all large price changes (negative and positive). Panel B shows the results for large price changes attributable to plausible causes related with drug innovation, presented in section 4.1 above. Both panels show pre and post-event periods related to large price changes, together with the mean abnormal returns (i.e. $\overline{A R}(0)$ or mean abnormal return on event time 0) for the event date.

Mean returns for the event date are $7.03 \%$ (positive large abnormal returns) and $-8.06 \%$ (negative large abnormal returns), respectively, with both values being statistically significant (see table 3 panel A). The values corresponding to pre-event periods are not statistically significant, and thus we conclude there is no reflection of any insider's information held by agents. Furthermore, there was no clear 
evidence of a short or long-term stock price reversal following a sharp one-day price fall or rise. Our analysis shows that the average cumulative abnormal returns for one, two, five and ten days following a large price increase or fall $(\overline{C A R}(+1,+1), \overline{C A R}(+1,+2), \overline{C A R}(+1,+5)$ and $\overline{C A R}(+1,+10)$, respectively) are not statistically significant. No clear (i.e. statistically significant) signal was found, after a significant price change, in the direction opposite to the trend. In other words, the prices continued to move in the direction of the large price movement for some time. Similar results were found by Cox and Peterson (1994), who reported that abnormal longer-term returns are negative after a large one-day fall. Hence, our main conclusion is that, for the stocks considered, which feature high market liquidity, overreaction did not lead to subsequent price reversals, either in the short or the long term. Therefore, large price changes of the type examined are not systematic and thus not potentially profitable. On the other hand, the mean cumulative abnormal returns between \pm 2 days is statistically significant for positive and negative large abnormal returns, at $9.85 \%$ and $-12.76 \%$, respectively, and it is greater for negative large price changes than for positive ones. 
Table 3. Overreaction tests for large stock price changes.

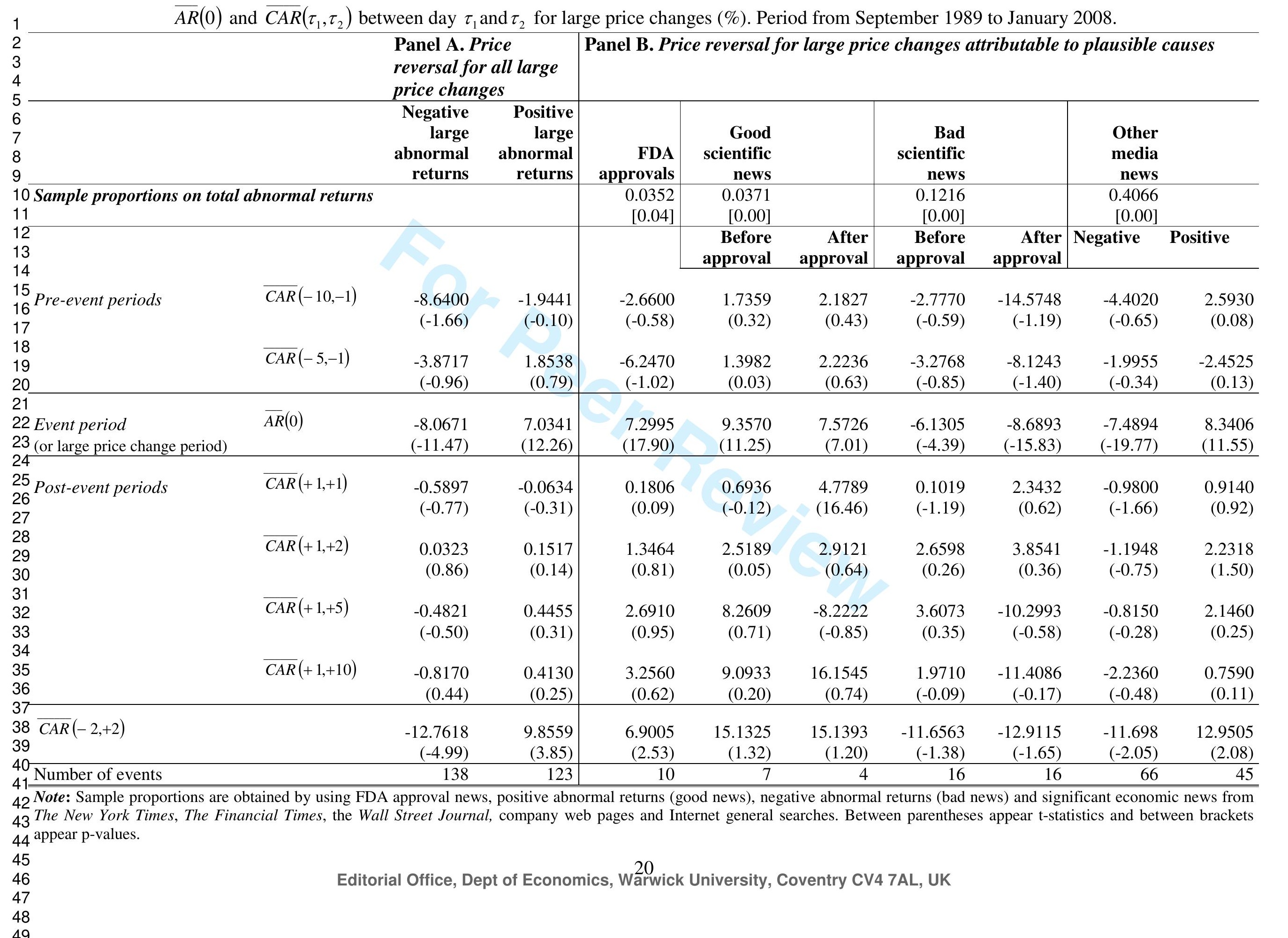


Table 3 (Panel B) shows the following possible causes of large price fluctuations; FDA approvals, good news from medical publications and clinical trials, bad news related to scientific knowledge, and other media news (distinguishing between positive and negative abnormal returns). Moreover, for both good and bad news we analyse separately those occurred before/after the innovation date (FDA approval). Abnormal returns for the event date were positive for FDA approvals, good scientific news and positive extreme price changes related to other news. These results are in line with Woolridge and Snow (1990) and Sharma and Lacey (2004). The effect of good news released before the innovation date is larger than the effect of good news release after that date. However, no price reversal was observed. Although FDA approvals produced greater abnormal profitability than did good scientific news, the largest effects on profitability were produced by other media news. In fact, the largest spike was caused by positive other media news and the sharpest fall, by negative other media news. Drug innovation (FDA approvals and good scientific news) was always associated with positive abnormal stock returns.

\section{Discussion}

This paper discusses the relationship between innovation and other news produced during the drug R\&D process, and the stock market price fluctuations of leading international pharmaceutical firms.

We examined extreme changes in daily stock prices to identify outliers; these outliers were then matched to approvals of new products, and other scientific and regulatory news. In all, we identified 261 abnormal market-adjusted daily returns. As a rule, these returns occurred on the same day as or the day after a significant news item, but on rare occasions they occurred a day before, or several days after, the news was published.

Our study concludes that there is a great deal of variability among recalls and withdrawals; some have considerable effects while others have none at all. All drugs, of course, are not equal; some 
develop a high level of demand, or account for a large share of the company's total sales, while some have only small sales.

Since the FDA generally makes its withdrawal announcements some time before its European equivalent, the EMEA, abnormal returns generally occur on the day of the FDA announcement and not when the EMEA notifies the same drug's compulsory recall from the European market.

In summary, of the 261 extreme abnormal price movements found, only $10(3.8 \%)$ corresponded to the launching of new products. Those 10 represent only $0.6 \%$ of the 1721 new drugs approved in the US during the period in question (620 of the 1721 were manufactured by the firms in our sample). The R\&D process and the approval of new drugs are highly regulated and standardized, and so investors are able to take positions in the market on the basis of the partial information published regarding previous clinical trials. On the negative side, 31 of the 261 abnormal returns (11.9\%) corresponded to recalls of drugs because of unacceptable side effects.

We found no evidence of market overreaction or backlash. Therefore, we conclude that large price changes do not lead to subsequent price reversals, either in the short or the long term, for the pharmaceutical stocks. There was no overreaction in the shocks associated with the introduction of new products. The efficient market hypothesis, thus, is fulfilled, preventing traders from being able to take advantage of knowledge of systematic patterns in market reactions following events related to innovation.

Our study has some limitations and potential biases. The media give more play to bad news than to good, and possibly the fact that there were 31 items of scientific bad news as outliers, as opposed to 20 good ones, is due to that publication bias. Another potential bias is temporal, since the companies' websites include press releases only for recent years and hence the detection of attributable causes for outliers is more likely for recent years than for the 1990s. This bias applies in particular to companies that resulted from mergers during the period under study, like Novartis and Sanofi-Aventis. A third potential bias is related to size and place. The press in general is more likely to publish news about big Editorial Office, Dept of Economics, Wärwick University, Coventry CV4 7AL, UK 
companies than small ones, and the American press is more likely to publish news about American companies than European or Japanese ones. For this reason we found only one plausible scientific cause for a Takeda outlier, while the great majority of abnormal returns of the large American companies Merck and Roche are amply reflected in The New York Times Business section.

\section{References}

Ahmed,P., Gardella,J., Nanda,S. (2002). "Wealth effect of drug withdrawals on firms and their competitors". Financial Management, 31, 3, 21-41.

Ahmed,I. (2007). "The market return to pharmaceutical product approval". Unpublished manuscript. The University of Texas at Arlington.

Atkins,A.B. and Dyl,E.A. (1990). "Price reversals, bid-ask spreads, and market efficiency". Journal of Financial and Quantitative Analysis, 25, 535-547.

Beaver,W. and Landsman,W.R. (1981). "Note on the behaviour of residual security returns for winner and loser portfolios". Journal of Accounting and Economics, 3, 3, 233-241.

Bollerslev,T. and Wooldridge,J.M. (1992). "Quasi-maximum likelihood estimation and inference in dynamic models with time varying covariances". Econometric Reviews, 11, 143-172.

Bremer, M.and Sweeney,R.J. (1991). "The reversal of large stock price decreases". Journal of Finance, 46, 747-754.

Bremer,M., Hiraki,T. and Sweeney,R.J. (1997). "Predictable patterns after large stock price changes on the Tokyo stock exchange". Journal of Financial and Quantitative Analysis, 32, 345-365.

Challet,D. and Stinchcombe,R. (2003). "Limit order market analysis and modelling: on a universal cause for over-diffusive prices". Physica A, 324, 141-145.

Chan,L., Lakonishok,J. and Sougiannis,T. (2001). "The Stock Market Valuation of Research and Development Expenditures". The Journal of Finance, 56, 2431-2456.

Chaney,P.K., Devinney,T.M. and Winer,R.S. (1991). "The impact of new product introductions on the market value of firms". Journal of Business, 64, 4, 573-610.

Cox, D.R. and Peterson, D.R. (1994). "Stock returns following large one-day declines: evidence on short-term reversals and longer-term performance". Journal of Finance, 49, 255-267.

Danzon,P.M., Chao,L.W. (2000). “Does regulation drive out competition in pharmaceutical markets?”. Journal of Law \& Economics, 23, 311-357.

DeBondt,W.F.M. and Thaler,R. (1985). “Does the stock market overreact?”. Journal of Finance 40, 793-808.

DiMasi,J. A. (1995). "Success rates for new drugs entering clinical testing in the United States". Clin Pharmacol Ther, 58, 1-14.

Dowdell,T., Govindaraj,S. and Jain,P. (1992). “The Tylenol incident, ensuing regulation, and stock prices". Journal of Financial and Quantitative Analysis, 27, 2, 283-301.

Dranove,D. and Olsen,C. (1994). "The Economic Side Effects of Dangerous Drug Announcements". Journal of Law \& Economics, 37, 323-348.

Eddy,A.R. and Saunders,G.B. (1980). "New product announcements and stock prices". Decision Sciences, 11, 1, 90-97.

Efremidze,L. (2007). "Firm Strategies and Stock Market Values in Biotechnology Industry." Claremont Graduate University. Working Paper.

Embi,PJ., Acharya,P., McCuistion,M., Kishman,C.P., Haag,D. and Marine,S. (2006). "Responding 
rapidly to FDA drug withdrawals: design and application of a new approach for a consumer health website". J Med Internet Res, 8, 3: http://www.jmir.org/2006/3/e16/

Farmer,J.D., Gillemot,L., Lillo,F., Mike,S. and Sen,A. (2004). "What really causes large price changes?". Quantitative Finance, 4, 383-397.

Filson,D. (2004). "The Impact of E-Commerce Strategies on Firm Value: Lessons from Amazon.com and its Early Competitors". Journal of Business, 77, 2, 135-154.

Geroski,P., Machin,S. and Van Reenen,J. (1993). "The Profitability of Innovating Firms". Rand Journal of Economics, 24, 2, 198-211.

Grabowski,H., Vernon,J. and DiMasi,J. (2002). "Returns on Research and Development for the 1990s New Drug Introductions". Pharmacoeconomics, 20, 3, 11-29.

Hara,T. (2003). Innovation in the Pharmaceutical Industry: The Process of Drug Discovery and Development, Cheltenham, U.K., Edward Elgar.

Jarrell,G. and Peltzman,S. (1985). "The Impact of Product Recalls on the Wealth of Sellers". Journal of Political Economy, 93, 512-536.

Lee,R. and Chen,Q. (2009). "The Immediate Impact of New Product Introductions on Stock Price: The Role of Firm Resources and Size!”. J Prod Innov Manag, 26, 97-107.

Mackinlay,A. (1997). "Event Studies in Economics and Finance”. Journal of Economic Literature, 35, 13-39.

Marcus,R., Swidler,S. and Zivney,T. (1987). “An Explanation of Why Shareholders' Losses are so Large After Drug Recalls”. Managerial and Decision Economics, 295-300.

Nelson,D. (1991). "Conditional heteroskedasticity in asset returns: A new approach". Econometrica, $59,347-370$.

Nicholson,S., Danzon,P. and McCullough,J. (2005). "Biotech-Pharmaceutical alliances as a signal of asset and firm quality". Journal of Business, 78, 4, 1433-64.

Oberholzer-Gee,F. and Inamdar,SN. (2004). "Merck's recall of rofecoxib. A strategic perspective". N Engl J Med., 351, 2147-9.

Park,J. (1995). "Market microstructure explanation for predictable variations in stock returns following large price changes". J. Finan. Quant. Anal., 30, 241-256.

Roberts,P.W. (1999). "Product Innovation, Product-Market Competition, and Persistent Profitability in the U.S. Pharmaceutical Industry”. Strategic Management Journal, 20, 7, 655-670.

Sharma,A. and Lacey,N. (2004). "Linking Product Development Outcomes to Market Valuation of the Firm: The Case of the U.S. Pharmaceutical Industry". Journal of Product Innovation Management, 21, 297-308.

Shi,C. (2003). "On the trade-off between the future benefits and riskiness of R\&D: a bondholders' perspective". Journal of Accounting and Economics, 35, 227-254.

Trusheim,M.R., Berndt,E.R. and Douglas,F.L. (2007). "Stratified medicine: Strategic and economic implications of combining drugs and clinical biomarkers". Nature Reviews, 6, 287-293.

Weber,P. and Rosenow,B. (2006). "Large stock price changes: volume or liquidity?". Quantitative Finance, 6, 1, 7-14.

Wong,M.C.S (1997), “Abnormal Stock Returns Following Large One-day Advances and Declines: Evidence from Asian-Pacific Markets”. Financial Engineering and Japanese Markets, 4, 71-177.

Woolridge,R.J. and Snow,C.C. (1990). "Stock market reaction to strategic investment decisions". Strategic Management Journal, 11, 5, 353-363.

Zawadowski,Á., Andor,G. and Kertész,J. (2006). "Short-term market reaction after extreme price changes of liquid stocks", Quantitative Finance, 6, 4, 283-295.

Xu,B. (2006). "R\&D strategy and stock price volatility in the biotechnology industry". Review of Accounting and Finance, 51, 1, 59-71. 